\title{
EDUCACIÓN
}

\section{Conocimiento que poseen padres y cuidadores de niños del "Centro Educativo Infantil ABC Children's Center" de Asunción, sobre la importancia del apego seguro y su implicancia en el proceso de aprendizaje}

\author{
Alda Noelia Ríos Urbieta ${ }^{1}$
}

\section{Resumen}

Introducción: En la actualidad se puede observar que a causa de la calidad de vida costosa y las necesidades básicas de una familia, así como el deseo de realización laboral, obliga a muchos padres a encomendar el cuidado de sus hijos pequeños a otras personas; para continuar trabajando en busca de recursos económicos para el sustento de su familia; en algunos casos los encargados del cuidado de sus hijos son familiares cercanos como abuelos, tíos, hermanos, etc.; en otros casos niñeras y en los últimos años se ha visto de forma más reiterativa, el de recurrir a Centros Infantiles, no solamente como un espacio en donde los niños puedan ser cuidados, sino por el aprendizaje que puedan ir adquiriendo en esos lugares a través de la estimulación oportuna y de acuerdo a lo acorde a las capacidades de cada edad, y también por la socialización que estos centros permiten no solamente con sus pares, sino con las encargadas de sala que aparte del cuidado en higiene, alimentación y estimulación, realizan el papel de contención emocional para el niño que se encuentra vulnerable al ser alejado de sus padres a tan corta edad. La contención emocional está muy ligada al vínculo afectivo que se forma entre el niño y una figura adulta significativa de confianza que por lo general son los progenitores o los encargados del cuidado del mismo. "La teoría del apego considera la tendencia a establecer lazos emocionales íntimos con individuos determinados como un componente básico de la naturaleza humana, presente en forma embrionaria en el neonato y que prosigue a lo largo de la vida adulta, hasta la vejez. Durante la infancia, los lazos se establecen con los padres o los padres sustitutos, a los que se recurre en busca de protección, consuelo y apoyo". El interés por este tema nace a partir de ampliar los conocimientos que se tiene sobre el apego seguro y acerca de la influencia que posee el mismo en el proceso de aprendizaje. Trabajo de campo realizado entre junio y agosto del 2017. El "Centro Educativo Infantil

\footnotetext{
1. Facultad de Humanidades y Ciencias de la Educación, Universidad Iberoamericana, Paraguay. Tesis para la Licenciatura en Psicopedagogía.

Proyecto financiado por el CONACYT. PROCIENCIA con recursos del Fondo para la Excelencia de la Educación e Investigación - FEEI del FONACIDE.

E-mail: rios.urbieta@gmail.com

DOI: 10.26885/rcei.foro.2017.99
} 
ABC Children's Center"es una institución de carácter privado y cuenta con 180 alumnos.

Objetivo: Analizar el nivel de conocimiento que poseen padres y cuidadores de niños del "Centro Educativo Infantil ABC Children's Center" de la ciudad de Asunción, sobre la importancia del apego seguro y su implicancia en el proceso de aprendizaje.

Material y Método: Diseño no experimental de tipo descriptivo y un enfoque cualicuantitativo. Se utilizó la técnica de la encuesta, con cuestionarios de preguntas abiertas y cerradas administradas a padres de niños que asisten a dicho Centro Infantil y entrevistas a docentes o encargadas de sala, del área de Maternal. La muestra seleccionada fue de cincuenta padres de familia de niños de 0 a 3 años que asisten al "Centro Educativo Infantil ABC Children's Center" de la ciudad de Asunción y cuatro encargadas de sala de niños de 0 a 3 años, del mencionado centro.

Resultados y Conclusiones: La mayoría de los padres de niños, poseen conocimiento acerca del apego seguro directamente relacionado a sus hijos. En cuanto a la importancia del vínculo afectivo entre el niño y sus padres, algunos testimonios de los padres de familia fueron: Que el Apego seguro es el vínculo emocional que establece el niño con los padres, el cual otorga al niño seguridad y desarrollo personal, una manera de contacto físico constante con el bebé, otorgando seguridad emocional. Que es importante responder a las necesidades del niño con cariño, alzándolo para darle consuelo, porque el bebé necesita estar próximo a su madre, en sus brazos, protegido y mimado. El niño se siente aliviado y seguro en compañía de su principal cuidador. El apego seguro es el vínculo que se genera desde el nacimiento del niño y ayuda a su desarrollo psicológico y emocional del niño, se trata de un contacto físico con los padres, pero equilibradamente, dejando al niño ser seguro y tomando decisiones en ciertas situaciones. En relación a la importancia de la seguridad emocional del niño, expresaron que el niño emocionalmente seguro se relaciona y aprende mejor, mencionaron que el niño estimulado mediante los sentidos y afecto, aprende mejor. Gracias a ello tiene una mayor tranquilidad y seguridad para su desarrollo. Si el niño se siente seguro de sí mismo el aprendizaje es más provechoso e integral. Cualquier persona que se sienta seguro, reconocido, querido y en un ambiente de comprensión y contención emocional puede relacionarse sin problemas en la sociedad. Algunos padres expresaron que, un niño emocionalmente feliz está mucho más dispuesto y motivado para aprender y mejorar sus habilidades; debido a que el equilibrio afectivo y emocional están vinculados con el área cognitiva y motriz. Una vez satisfechas sus necesidades básicas, ya están preparados para aprender. En cuanto al conocimiento de las docentes del mencionado centro infantil sobre el apego seguro manifestaron que se ven las características en los niños que tienen apego seguro cuando socializan más, se sueltan más como dice su nombre se sienten más seguros en el ambiente o en su entorno mismo. El establecer algún vínculo afectivo te 
proporcione seguridad, apego seguro. Es una división de apego en la cual el niño está preparado para afrontar situaciones pero siempre observando que su referencia este cerca. En relación a que los niños emocionalmente seguros y saludables aprovechan mejor las enseñanzas, las entrevistadas señalaron que si aprovechan mucho mejor, están mucho más activos, más despiertos, se prestan más a las actividades, disfrutan más de las actividades entonces eso hace que ellos aprendan y absorban mucho más rápido o mucho más fácil. Un niño cuando no está seguro de sí mismo, genera eso la frustración, se frustra con mayor facilidad, el berrinche que si bien es característico, es como que el niño que tiene un vínculo afectivo seguro con los padres o con los adultos, y es más capaz de manejar sus emociones, si bien se va sentir frustrado, capaz lo va poder manejar, va tener rabietas pero no muy marcado digamos, Aprovechan mejor porque están al $100 \%$ pendiente de lo que estamos haciendo y disfrutan si o si, sin embargo los niños que no están tan saludables, es que no prestan atención, no disfrutan de los juegos a veces o de las consignas que dan durante la clase.

Palabras clave: conocimiento de padres y cuidadores, niños, apego seguro y proceso de aprendizaje.

\section{Referencias}

Bowlby, J. (2009). Una base segura: aplicaciones clínicas de una teoría del apego. Buenos Aires: Paidós.

Campos, A. (2010). Neuroeducación: uniendo las neurociencias y la educación en la búsqueda del desarrollo humano. Revista la Educación, 143.

Jacubovich, M., Bruzzo, M. \& Antolin, M. (2008). Escuela Maternal. Buenos Aires: Circulo Latino Austral.

Papalia, D., WendkosOlds, S. \& DuskinFeldman, R. (2009). Desarrollo Humano (11 $1^{\text {a }}$ ed.). México, D.F.: McGraw-Hill Companies/Interamericana Editores. 